FACTA UNIVERSITATIS

Series: Philosophy, Sociology, Psychology and History Vol. 20, N² 2, 2021, pp. i - iii

https://doi.org/10.22190/FUPSPH210200iO

Editorial

\title{
THE PSYCHOSOCIAL ASPECTS OF INFERTILITY
}

Two basic domains, fundamental for the formation of one's identity on the very eve of adulthood, are love and work (Arnett \& Tanner 2006; Erikson 1968; Schwartz, Côté \& Arnett 2005). It is in these domains that young adults establish, adopt and clarify their life goals, along with completing another important task which originated in modern societies: finding a meaningful life (Mayseless \& Keren 2013). Most people have a sense of active inclusion in choosing the direction the course of their life will take. They follow the developmental paths which lead in a certain direction, in the sense of realizing long-term goals, and, when necessary, giving up on non-attainable goals (Hechhausen, Wrosch \& Schulz 2010). The goals that people aspire to are mental representations of desired outcomes of life-course transitions and developmental processes. Often these desired outcomes are strongly influenced by what society has come to identify as a developmental task for a given age or life-course transition, as noted early on by Havighurst (1952). One of the values which society supports strongly is pronatalism: the idea is that parenthood and raising children are the central focus points of adult life. This concept could be seriously criticized (Carroll 2012), but for the purpose of this editorial and the articles which follow it is important to point out that having and raising children is viewed by most people as a desired outcome, an important developmental or life goal. Not fulfilling the norm of pronatalism, from the point of view of society, represents deviant behavior and could lead to the marginalization of an individual and the formation of a stigmatized identity (Mård 2020; Park 2002).

The motivational theory regarding the course of one's life makes the claim that even when they are faced with obstacles, disappointments and failures, people have the extraordinary ability to stay on course and to maintain a sense of personal agency (Hechhausen, Wrosch \& Schulz 2010). However, infertility and treating infertility can very roughly and over a long period of time disrupt the realization of a significant life goal, and deplete the capacity of an individual to overcome hardships. That is, if we were to revert to life domains, infertility will more or less disrupt the formation of an identity in the domain of love, exhaust the resources for self-realization in the field of work, and bring into question the meaningful life of a young adult.

Today it is clear that infertility is a phenomenon which is much more complex than its medical definition - "a disease of the reproductive system defined by the failure to achieve a clinical pregnancy after 12 months or more of regular unprotected sexual intercourse" (WHO-ICMART revised glossary). Infertility encompasses complex psychological and social aspects, which should as a necessity be taken into consideration when analyzing the life crisis which infertility provokes. We consider it important to discuss such topics, since psycho-social support is not an integral part of the infertility treatment in Serbia, even though it should be. Nowadays couples are left to their own devices to seek support they will fund themselves, if they are able to, if they want to, or if they recognize the need to. At the same time, one should know that the success of the treatment (usually IVF) and later mental health depend on the individual experiences of the individuals taking part in the 
treatment (Frederiksen et al. 2015; Rocfkliff et al. 2014). This does not mean that all couples have difficulty overcoming these problems - research indicates that there are significant differences in the emotional reactions to infertility and its (unsuccessful) treatment (An et al. 2013; Rockliff et al. 2014; Verhaak et al. 2005). On the other hand, the fact that not everyone encounters difficulties does not mean that support programs should not exist. The most stressful periods for couples taking part in the IVF treatment are the period of waiting for the results of the pregnancy test and the period after failed cycles (Bolvin \& Lancastle 2010; Bringhenti et al. 1997; Verhaak et al. 2005).

At the beginning of this thematic issue, we can read much about delaying childbirth and infertility. Even though deferring parenthood is usually related to the requirements and values of modern society, we should not neglect the physiological limitations of individual choice caused by the age of the individual. They are followed by articles which deal with factors which contribute to the better adaptation to infertility, that is, the IVF procedure. What contributes to more easily overcoming infertility, among other things, is a shared sense of community and intimacy among partners; this kind of partner relationship is more significant than the perception of broader social support, even though both factors are predictors of positive and negative affectivity. It is also possible to read a qualitative study on the perception of stigma attached to women with their own experiences of IVF, as well as an overview of the qualitative studies on the experiences of women with infertility. Qualitative studies are vital for understanding the phenomenon, since the narratives correctly complete the results obtained by a standardized questionnaire. And finally, we encounter a topic which represents an additional specific challenge: the question of preserving fertility among young women treated for cancer - the so-called double trauma.

There are topics which have not been included, even though we had planned to include some of them. For example, are there any specificities in experiencing infertility in the Romani population? How do couples whose treatment was unsuccessful adapt to involuntary childlessness; how frequent is the prolonged grief disorder (PGD)? What are the attitudes towards gamete donation in the general population and among couples dealing with infertility; why has donation not been met with greater success in the Republic of Serbia even though it is legal? What are the attitudes towards surrogate motherhood - what do women of a child-bearing age think of this option?

Still, we believe that this thematic issue has made another step in the direction of promoting awareness about the significance and importance of psychosocial issues in our environment and that the published texts will facilitate the study and discussion of psychosocial aspects of reproductive health. Therefore, we are taking a step in the right direction - towards better conditions for overcoming infertility.

\section{REFERENCES}

An, Y., Z. Sun, L. Li, Y. Zhang, \& H. Ji. "Relationship between psychological stress and reproductive outcome in women undergoing in vitro fertilization treatment: Psychological and neurohormonal assessment". Journal of Assisted Reproduction and Genetics 30, 1 (2012): 35-41. doi:10.1007/s10815-012-9904-X

Bringhenti, F., F. Martinelli, R. Ardenti, \& G. B. La Sala. "Psychological adjustment of infertile women entering IVF treatment: Differentiating aspects and influencing factors". Acta Obstetricia et Gynecologica Scandinavica 76 (1997): 431-437.

Arnett, J. J. \& J. L. Tanner. Emerging adults in America: Coming to age in the 21st century. Washington, DC: American Psychological Association, 2006. 
Bolvin, J., \& D. Lancastle. "Medical Waiting Periods: Imminence, Emotions and Coping”. Women's Health 6, 1 (2010): 59-69. doi:10.2217/whe.09.79

Carroll, L. The Baby Matrix. LiveTrue Books, 2012.

Erikson, E. H. Identity: Youth and Crisis. New York, NY: Norton, 1968.

Frederiksen, Y., I. Farver-Vestergaard, N. G. Skovgard, H. J. Ingerslev, \& R. Zachariae. "Efficacy of psychosocial interventions for psychological and pregnancy outcomes in infertile women and men: A systematic review and meta-analysis". BMJ Open 5, 1 (2015): e006592-e006592. doi:10.1136/bmjopen-2014-006592

Havighurst, R. J. Developmental tasks and Education. New York, NY: McKay Company, 1952.

Hechhausen, J., C. Wrosch \& R. Schulz. "A motivational theory of life-span development". Psychology Review 117, 1 (2010): 32. doi:10.1037/a0017668

Mård, M. "Involuntary childlessness at work: Experiences of emotion work, unfair marginalization and inadequacy". Nordic journal of working life studies (2020): 1-19. doi: 10.18291/njwls.123623

Mayseless, O. \& E. Keren. "Finding a meaningful life as a developmental task in emerging adulthood". Emerging Adulthood 2, 1 (2013): 63-73. doi:10.1177/2167696813515446

Park, K. "Stigma management among the voluntarily childless". Sociological Perspectives 45, 1 (2002): 21-34. doi: $10.1525 /$ sop.2002.45.1.21

Rockliff, H. E., S. L. Lightman, E. Rhidian, H. Buchanan, U. Gordon \& K. Vedhara. "A systematic review of psychosocial factors associated with emotional adjustment in in vitro fertilization patients". Human Reproduction Update 20, 4 (2014): 594-613. doi:10.1093/humupd/dmu010

Schwartz, S. J., J. E. Co^te' \& J. J. Arnett. "Identity and agency in emerging adulthood: Two developmental routes in the individualization process". Youth and Society 37 (2005): 201-229.

Verhaak, C. M., J. M. J. Smeenk, A. van Minnen, J. A. M. Kremer \& F. W. Kraaimaat. "A longitudinal, prospective study on emotional adjustment before, during and after consecutive fertility treatment cycles". Human Reproduction 20, 8 (2005): 2253-2260. doi:10.1093/humrep/dei015

WHO-ICMART revised glossary. Accessed January 14. 2021. https://www.who.int/teams/sexual-andreproductive-health-and-research/key-areas-of-work/fertility-care/infertility-definitions-and-terminology

Jelena Opsenica Kostić

University of Niš, Serbia

Faculty of Philosophy

Department of Psychology 